\title{
VARIASI MODEL SUPERVISI PEMBELAJARAN (STUDI KASUS : SD MADINA ISLAMIC SCHOOL, TEBET, JAKARTA SELATAN)
}

\author{
Hidayatus Syarifah \\ STAI Madinatul Ilmi Depok, \\ shiedayah@yahoo.com
}

\begin{abstract}
Abstrak: Supervisi pembelajaran yang variatif dapat meningkatkan kualitas pendidikan. Penelitian ini bertujuan untuk mendeskripsikan model supervisi yang dikembangkan oleh SD Madina Islamic School. Penelitian menggunakan pendekatan kualitatif deskriptif-naturalistik. Melalui triangulasi teknik pengumpulan dan pengolahan data, didapatkan temuan penelitian bahwa SD Madina Islamic School memadukan model supervisi pembelajaran secara variatif, berprinsip rahasia dan spontanitas, serta bermanfaat habitualiasasi guru dalam pembelajaran. Melalui perpaduan kurikulumnya yakni DIKNAS, Al-Azhar Cairo, dan Cambridge, maka variasi supervisi pembelajaran diterapkan dengan berbagai kriteria penilaian khusus, guna menghasilkan penilaian dan bimbingan yang optimal, terarah, dan otentik.
\end{abstract}

Kata Kunci : Model Supervisi Pembelajaran, Supervisi Pendidikan, Supervisi Terpadu.

Abstract:Variations of learning supervision models can improve the quality of education. This research aims to describe the supervision models developed in SD Madina Islamic School. The research used qualitative descriptive-naturalistic approach. Through triangulation of data collection and processing techniques, the findings of research that SD Madina Islamic School combined models of supervision of learning, secretive and spontaneous principles, and has the benefit for habits teachers in learning. Through the mix of curriculum namely DIKNAS, AIAzhar Cairo, and Cambridge, variations of learning supervision are applied using special assessment criteria, to produce an optimal, directed, and authentic assessment and guidance. Keywords: Supervision of Learning Models, Supervision of Education, Integrated Supervision.

\section{PENDAhuluan}

Kualitas Pendidikan di Indonesia masih memprihatinkan. Jaringan Pemantau Pendidikan Indonesia (JPPI) dalam penelitian Right to Education Index (RTEI) menyatakan indeks kualitas pendidikan di Indonesia belum memadai dengan skor 77\%, dan masih di bawah Ehtiopia dan Filipina (Rahayu, DetikNews, 23 Maret 2017). Sahroji (Okezone News, 25 November 2017) menegaskan bahwa Indonesia menempati posisi 108 di dunia dengan skor 0,603.

Fakta tentang minimnya kualitas pendidikan di Indonesia, membutuhkan perhatian dan penanganan yang cukup serius. Salah satu upaya yang harus dilaksanakan adalah peningkatan kualitas supervisi pembelajaran. Mengapa demikian? Melalui supervisi, pembelajaran dapat dilihat dan dinilai secara langsung dan otentik terkait kekurangan dan kelebihannya. Segala kekurangan dalam pembelajaran menjadi bahan evaluasi bersama dan mendapatkan tindak lanjut, hingga kemudian menghasilkan pembelajaran yang optimal. Dengan demikian, supervisi yang berkualitas akan menghasilkan perbaikan mutu pendidikan, khususnya kinerja guru dalam pembelajaran menjadi terarah, sistematis, terkendali, memuaskan dan tergambar dengan jelas sesuai antara kenyataan dengan yang diharapkan.

Urgensi supervisi pembelajaran dalam dunia pendidikan, menuntut adanya supervisor yang kompeten. Sagala (2013: 242), mengemukakan bahwa supervisor dituntut mampu melihat guru dalam perencanaan pengembangan staf, dengan menciptakan suatu cara pengembangan profil. Sementara itu, Supardi (2013: 89), menjelaskan bahwa supervisi pembelajaran sangat

Jurnal Manajemen Pendidikan, Vol 12, No 2., 
penting untuk melakukan pengendalian, arahan, observasi, dan menilai segala yang berlaku di dalam kelas. Oleh karena itu, menjadi supervisor bukan hal yang mudah. Kompetensi yang diharapkan tidak hanya sekedar memberi penilaian, namun lebih dari itu. Supervisor harus mampu mendalami perannya, dan mendalami pengenalan terhadap guru yang disupervisi olehnya. Sehingga guru yang disupervisi tidak sekedar mendapat masukan, namun memahami benar apa arti pembelajaran sesungguhnya mulai dari perencanaan hingga evaluasi.

Sementara itu, dalam rangka pencapaian kompetensi supervisor sesuai harapan maka dikembangkan model-model supervisi. Supardi (2013: 89) mengemukakan bahwa, modelmodel supervisi merupakan alternatif kepada supervisor dan guru yang disupervisi untuk mengatasi masalah yang timbul, seperti masalah hubungan supervisor dengan guru, guru-guru meragukan kepakaran supervisor, ketegangan emosi yang dialami guru-guru, perasaan takut, salah paham, dan lain sebagainya. Dengan demikian, model supervisi pembelajaran merupakan sebuah pendekatan atau cara yang dilakukan supervisor dalam menemukan permasalahan atau melakukan peningkatan kinerja guru.

Variasi model supervisi dapat menjadi acuan supervisor dan guru dalam menjalankan perannya agar lebih terarah dan berfokus (Supardi, 2013: 89). Selain itu, tidak menutup kemungkinan kreatifitas masing-masing supervisor diperlukan dalam praktiknya. Setiap model supervisi yang ada mempunyai kelebihan dan kekuatannya sendiri. Supardi (2013: 100) menegaskan untuk memilih model supervisi secara tepat dan sesuai dengan situasi agar proses supervisi berjalan dengan lancar. Sehingga, dapat dikatakan bahwa pemilihan model yang tepat merupakan indikator keberhasilan supervisi.

Berdasarkan paparan diatas, peningkatan mutu pendidikan khususnya dalam lingkup pembelajaran dapat dikatakan salah satunya dipengaruhi oleh keberhasilan melaksanakan supervisi. Keberhasilan tersebut berdampak pada mutu pembelajaran apabila memiliki tingkat kesesuaian terhadap situasi dan kondisi yang terjadi. Tentunya, setiap sekolah memiliki otoritas dalam menentukan model supervisi yang digunakan untuk menunjang mutu pendidikan di sekolahnya. Sehingga sangat wajar apabila terdapat perbedaan antara instansi satu dengan lainnya. SD Madina Islamic School juga menerapkan model supervisi yang belum tentu diterapkan di sekolah lain, atau juga telah diterapkan di sekolah lainnya. Sebagai pendalaman terhadap kajian tentang model supervisi yang telah diterapkan di SD Madina Islamic School, maka dalam kajian ini akan dipaparkan model supervisi yang diterapkan di SD Madina Islamic School Tebet.

Bertitik tolak dari fokus penelitian tersebut, maka dikembangkan rumusan masalah yaitu, "Bagaimana model supervisi pembelajaran yang diterapkan di SD Madina Islamic School?" Sementara itu, penelitian ini bertujuan untuk mendeskripsikan model supervisi yang dikembangkan oleh SD Madina Islamic School. Penelitian ini diharapkan dapat memberikan konstribusi alternatif untuk model supervisi pembelajaran di Indonesia baik secara teoritis maupun praktis.

\section{METODE PENELITIAN}

Penelitian menggunakan pendekatan kualitatif deskriptif-naturalistik. Penelitian ingin menghasilkan/ menggambarkan keadaan, kondisi/ situasi, peristiwa atau fenomena yang terjadi di lapangan tentang model supervisi pembelajaran di SD Madina Islamic School, dengan sebagaimana adanya (natural setting) melalui data tertulis dan non-tertulis.

Melalui triangulasi (Observasi, Wawancara, dan Studi Dokumen), didapatkan data primer yang bersumber dari kepala sekolah SD Madina Islamic School yang mempunyai tanggung jawab secara keseluruhan atas pelaksanaan supervisi pembelajaran di sekolah terkait. Sedangkan data sekunder, yaitu buku literatur, artikel dan dokumen yang berkaitan dengan masalah penelitian. 
Observasi dilakukan dengan melakukan pengamatan secara langsung dan mencatat peristiwa, kejadian, serta kegiatan selama proses pelaksanaan supervisi di Madina Islamic School. Selanjutnya, wawancara secara mendalam (in-depth interview) dan semi terstruktur dilakukan dengan pihak terkait, dan dilengkapi dengan studi dokumen yaitu mengumpulkan dokumendokumen terkait penelitian seperti profil lembaga, profil kegiatan, jadwal kegiatan, dan data lainnya yang sesuai dengan permasalahan. Agar penelitian terlaksana dengan baik, maka disusun pedoman observasi, wawancara dan studi dokumen.

Setelah tahap pengumpulan data, kemudian dilakukan analisis dan pengujian keabsahan data. Pada tahap ini digunakan dua metode yaitu: I) Triangulasi metode, yaitu membandingkan dan mencocokkan fenomena yang diperoleh peneliti di lapangan (berupa catatan selama observasi) dengan data yang diperoleh melalui wawancara dan studi dokumen; dan 2) Triangulasi data, yaitu membandingkan data-data dan bukti yang diperoleh dari situasi yang berbeda, meliputi 3 (tiga) sub jenis yaitu orang, waktu dan ruang. Artinya, peneliti akan mengambil dan menggali informasi dan data dari guru dan santri yang melakukan aktivitas sama dan melaksanakannya di waktu dan tempat yang berbeda.

\section{HASIL DAN PEMBAHASAN}

\section{PROFIL SD MADINA ISLAMIC SCHOOL}

Secara geografis, SD Madina Islamic School terletak di Jalan Tebet Dalam IV No.I, RT.I2/RW.I, Kecamatan Tebet, Kota Jakarta Selatan, Daerah Khusus lbukota Jakarta I28I0.

SD Madina Islamic School merupakan salah satu jenjang di sekolah Madina Islamic School, yang seluruhnya terdiri dari jenjang Sekolah KB, TK, SD, SMP, SMA. Sekolah yang didirikan oleh Riyanto Sofyan, B.S.E.E, MBA. Didirikan tahun 2004. Sekolah ini merupakan sekolah Islam terpadu nasional-plus yang menawarkan standar pendidikan yang Islami, nasional serta internasional dengan terintegrasi. Kurikulum yang diterapkan ada 3, yaitu: I) Kurikulum Nasional (DIKNAS); 2) Kurikulum al-Azhar (untuk materi Tahfidz, Islamic Studies, Arabic) di bawah koordinasi Dr. Moh. Syairozi Dimyathi, M.Ed. Azhari Islamic School- Branch of al-Azhar Cairo; dan 3) Kurikulum Internasional (CAMBRIDGE) untuk materi Matematika, Bahasa Inggris dan IPA.

Sekolah tersebut memiliki prinsip yang kuat untuk mengaplikasikan Islam dengan kaffah. Oleh karenanya, al-Qur'an dan as-Sunnah digunakan sebagai inti dan sumber yang paling tinggi dari semua keterampilan, ilmu dan pengetahuan serta kekuatan akademis dengan pendidikan global pada generasi yang akan tiba.

Konsep pendidikan yang ditawarkan Sekolah Madina Islamic School tersebut, selaras dengan perwujudan visi dan misi. Adapun visi Sekolah Madina Islamic School yaitu, "To be an integrated education institution which is able to produce generations with global capacities and have characters with integrity as insan kamil who are ready to build a civilized society." Visi tersebut menegaskan bahwa Sekolah Madina Islamic School mengharapkan menjadi sebuah instansi pendidikan terpadu yang dapat mewujudkan generasi berkapasitas global. Kapasitas global tersebut dapat membangun peradaban, yang berciri khas dan memiliki integritas sebagai insan kamil.

Selaras dengan adanya visi tercantum tersebut, maka misi yang dikembangkan oleh Sekolah Madina Islamic School antara lain: I) To produce students with straight aqeedah, appropriate worship, wide horizons, noble morals, creativity, independence and significant achievement in their lives, and optimum participation of the school's management; 2) To integrate science and knowledge into life, according to an Islamic view of life; dan 3) To develop and apply knowledge in globally qualified institutions based on universal Islamic values. Pengembangan misi tersebut, menegaskan bahwa melalui integrasi ilmu, pengetahuan, dan nilai kehidupan memberikan peluang bagi peserta didik untuk mewujudkan dirinya menjadi pribadi yang

Jurnal Manajemen Pendidikan, Vol 12, No 2., 
kompeten dalam pengetahuan, keterampilan, maupun afektifitasnya. Peserta didik dapat beraqidah lurus, berwawasan luas, berakhlaq mulia, cakap, kreatif, mandiri dan berprestasi. Selain itu, stakeholder sekolah pun menjadi lebih optimal. Dengan demikian, terciptanya sekolah yang berkualitas dan berkapasitas global berlandaskan nilai-nilai Islam yang universal dapat diwujudkan bersama-sama.

\section{VARIASI MODEL SUPERVISI PEMBELAJARAN}

\section{I) Pelaksana Internal Supervisi Pembelajaran}

Pelaksana kegiatan supervisi pembelajaran yang diterapkan di SD Madina Islamic School adalah tim manajemen khusus sekolah, wakil kepala sekolah bidang kurikulum serta didampingi juga kepala sekolah. Mulyasa (20 I 3b: I I I) mengemukakan bahwa supervisi sesungguhnya dapat dilaksanakan oleh kepala sekolah, namun dalam sistem pendidikan modern diperlukan supervisor khusus yang independent, guna meningkatkan objektivitas pembinaan dan pelaksanaan tugasnya.

Hakikatnya, pelaksanaan supervisi pembelajaran di sekolah paling utama dilaksnakaan oleh pihak internal sekolah. Dengan argumen, keberlangsungan proses pendidikan di sekolah secara nyata menjadi bagian tanggung jawab pihak internal itu sendiri. Oleh karenanya, tingkat intensitas partisipasi dan inovasi lebih terlihat, atas dasar tanggung jawab penuh tersebut demi peningkatan mutu pendidikan di sekolahnya. Dampak utamanya dapat menghasilkan penilaian yang benar-benar otentik.

\section{2) Supervisi Terstruktur Bulanan dan Tidak Terstruktur Spontanitas}

Pelaksanaan supervisi pembelajaran di SD Madina Islamic School terlaksana secara terstruktur dan tidak terstruktur. Secara terstruktur, pelaksanaan supervisi pembelajaran ditetapkan secara rutin setiap I (satu) bulan sekali. Hal ini senada dengan pendapat Mulyasa (20I3b: II5) bahwa supervisi kepada tenaga kependidikan harus dilaksanakan secara periodik. Oleh karena itu, sekolah harus menetapkan jadwal kegiatan supervisi secara rutin dalam jangka periodik tertentu, yang disepakati dan dipublikasikan. Adapun jadwal dalam supervisi pembelajaran dapat dilaksanakan oleh kebijakan masing-masing sekolah. Rutinitas ini menjadi aspek penting dalam peningkatan mutu pendidikan di suatu sekolah.

Sementara itu, supervisi tidak terstruktur yakni tidak terdapat jadwal terstruktur tentang urutan guru dalam pelaksanaan supervisinya. Supervisi yang dilaksanakan bersifat rahasia dan spontanitas. Berprinsip rahasia artinya hanya pihak manajemen yang mengetahui secara rinci informasi tentang jadwal urutan guru dalam pelaksanaan supervisi. Sedangkan berprinsip spontanitas artinya guru yang akan disupervisi harus siap sepenuhnya dalam waktu yang tidak ditentukan, dan secara spontan melaksanakan supervisi. Supervisor memasuki ruang kelas pada saat guru mengajar, melakukan pengamatan selama guru mengajar, melakukan evaluasi dan penilaian kepada guru. Adapun jika terdapat kekurangan dalam proses pembelajaran oleh seorang guru, maka akan diberikan bimbingan khusus kepada guru tersebut.

Penerapan prinsip spontanitas tersebut, beralasan agar dapat menetapkan penilaian sesuai realita atau kenyataan yang terjadi di dalam kelas pada saat guru mengajar. Sehingga diharapkan guru selalu waspada dan melakukan yang terbaik setiap harinya dalam mengajar, bukan hanya menyiapkan segala sesuatu secara baik hanya pada saat akan disupervisi saja. Meskipun demikian, prinsip spontanitas juga memiliki dampak negatif yakni dari segi kepuasan hati guru yang disupervisi, karena kecenderungan supervisor yang memiliki kaidahnya masingmasing sehingga mempunyai prosedur yang berbeda-beda (Supardi, 2013: 89).

Prinsip rahasia dan spontanitas tersebut selaras dengan pendapat Supardi (2013: 92) bahwa supervisor dapat melakukan observasi dengan masuk ke dalam kelas ketika guru sedang melakukan kegiatan pembelajaran dan mengobservasi pembelajaran guru. Proses observasi melibatkan tiga fase yaitu perbincangan sebelum observasi, pada saat observasi dan pasca observasi. Selama perbincangan observasi, kepala sekolah mengambil data yang berkaitan 
pembelajaran seperti nama guru, kelas yang diajar, mata pelajaran, tanggal dan waktu. Di samping itu, kepala sekolah juga perlu melihat keadaan fisik kelas apakah menggambarkan suasana pembelajaran atau sebaiknya.

\section{3) Supervisi Pembelajaran Bermanfaat Habitualisasi}

Supervisi pembelajaran yang terlaksana di Madina Islamic School memiliki manfaat dan dampak yang positif terhadap peningkatan mutu sekolah. Secara khusus, manfaat yang dirasakan bagi sekolah ini adalah adanya pembiasaan atau habit disiplin bagi guru selaku penggerak dalam roda pembelajaran yang berinteraksi langsung dengan peserta didik.

Pembentukan habit yang baik memang tidak mudah. Dengan adanya rutinitas dan komitmen yang tinggi dalam melaksanakan suatu hal yang positif, tentu akan berdampak pada pembentukan habit (kebiasaan) pada pelakunya. Begitu juga dengan prinsip spontanitas dalam supervisi pembelajaran yang diterapkan di SD Madina Islamic School tersebut, yang membentuk kebiasaan bagi guru di sekolah terkait untuk melaksanakan peran dan tanggung jawabnya dalam pembelajaran secara maksimal setiap harinya. Pembelajaran optimal yang dilakukan guru tidak hanya saat ada kegiatan supervisi saja.

\section{4) Ruang Lingkup Supervisi Pembelajaran yang Komprehensif}

Ruang lingkup pelaksanaan supervisi pembelajaran di SD Madina Islamic School bersifat komprehensif, meliputi: I) cara mengajar guru; 2) display kelas; 3) kelengkapan administrasi guru seperti silabus, RPP, Program Tahunan (PROTA), Program Semester (PROSEM), Penentuan KKM, dan lain sebagainya; dan 4) report / hasil belajar peserta didik per-satu bulan.

Ruang lingkup supervisi tersebut, ditegaskan dalam pedoman pengembangan administrasi dan Supervisi Pendidikan oleh Depag RI (2000: 40-46), bahwa supervisi pendidikan dan pengajaran memiliki tiga unsur yang saling berkaitan, yakni unsur personal, material, dan operasional. Oleh karena itu, selain guru yang dilakukan supervisi, juga aspek adminitratif dan operasional pada guru selama pembelajaran juga menjadi bahan supervisi. Ketiga aspek tersebut secara berkesinambungan dan terus menerus untuk dilakukan supervisi, guna mengoptimalkan kualitas pembelajaran yang ada.

Proses pembelajaran sangat berkaitan erat dengan pembinaan guru, sehingga dalam kegiatan supervisi pembelajaran aspek utama yang harus diperhatikan adalah guru. Supardi (20I3: 9I) menegaskan bahwa "guru-guru seharusnya diberi bimbingan, nasihat atau bantuan oleh kepala sekolah dalam merancang, menyelaras dan melaksanakan kurikulum di sekolah.” Semnetara itu, Sahertian, dkk (1990: 84-85) mengemukakan bahwa supervisor bertugas membantu guru memperbaiki situasi pembelajaran pada makna luas, yang mencakup beberapa komponen peningkatan yaitu: I) penjelasan kaitan antara tujuan-tujuan pendidikan; 2) bimbingan pengalaman belajar dan keaktifan belajar siswa; 3) penggunaan berbagai sumber dan media belajar; 4) penerapan metode dan teknik mengajar; 5) analisa terhadap kesulitankesulitan belajar dan kebutuhan siswa; dan 6) menilai proses dan hasil pembelajaran siswa. Oleh karena itu, cara mengajar guru menjadi tujuan utama dalam pelaksanaan supervisi pembalajaran.

Sementara itu, supervisi pembelajaran terkait administrasi pembelajaran dilakukan secara rutin terhadap pemeriksaan lesson plan atau RPP bagi setiap guru yang akan mengajar. Proses pelaksanaannya dalam waktu yang ditentukan setiap bulannya, kelengkapan berkas sudah terlebih dahulu diletakkan di meja supervisor untuk kemudian oleh supervisor dilakukan analisis dan penilaian. Dari lesson plan tersebut, supervisor dapat melakukan penilaian mendalam juga terhadap karakteristik masing-masing guru yang pada dasarnya memiliki kepribadian dan cara mengajar yang berbeda-beda.

\section{5) Aplikasi Model Supervisi Pembelajaran yang Variatif}

Pelaksanaan supervisi pembelajaran di SD Madina Islamic School mengkombinasikan berbagai model supervisi pembelajaran yang ada. Meskipun praktiknya tidak menerapkan setiap 
model supervisi secara utuh dalam satu periode supervisi. Variasi model supervisi pembelajaran digunakan agar sekolah dapat secara komprehensif, autentik, dan mendalam dalam pelaksanaan supervisi pembelajaran di SD Madina Islamic School.

Beberapa model supervisi pembelajaran yang diterapkan di SD Madina Islamic School diantaranya: I) Model supervisi pengembangan; 2) Model Jendela Johari; 3) Model supervisi berbeda; 4) Model supervisi bersama; 5) Model supervisi inkuiri; 6) Model supervisi klinik; dan 7) Model supervisi saintifik, klinis dan artistik (Aedi, 20I4: 55-56; Supardi, 20I3: 89-90).

Aplikasi model supervisi yang dilaksanakan secara variatif di SD Madina Islamic School melalui beberapa kegiatan. Pertama, penerapan model supervisi pengembangan di SD Madina Islamic School dilaksanakan dengan pemberian training atau pelatihan-pelatihan khusus kepada guru-guru di Madina Islamic School secara terstruktur. Hal tersebut agar kemampuan dan keprofesionalan guru dapat selalu di-upgrade demi meningkatakan kualitas pembelajaran. Model supervisi pengembangan tersebut dikembangkan oleh Glickman, Gordon dan Ross Gordon untuk meningkatkan taraf profesional di kalangan guru-guru, perlu diberi pembekalan dengan pendekatan dan teori-teori baru tentang pembelajaran. Guru juga perlu diberi peluang untuk mengikuti kuliah yang dianjurkan oleh Kementerian Pendidikan Nasional atau Dinas Pendidikan dan sebagainya, melanjutkan pelajaran dan menghadiri kuliah pendalaman seperti ceramah, seminar, bengkel dan program pengembangan staf (Supardi, 2013: 90-93). Model supervisi pengembangan mengarahkan pada sejumlah tugas dan keterampilan yang meningkatkan dialog pembelajaran dan pertumbuhan serta pengembangan profesionalisme guru, agar kualitas pengajarannya berkualitas. Oleh karena itu, supervisor dituntut mampu mengidentifikasi bakat dan kemampuan guru untuk diikutsertakan dalam program pelatihan atau penataran dalam upaya pengembangan staf (Aedi, 2014: 63; Sagala, 2013: 242).

Kedua, model jendela Johari diterapkan dengan adanya penekanan hubungan antara supervisor dan guru yang disupervisi. Model ini digunakan oleh supervisor berkaitan dengan kompetensi pengetahuan guru terhadap pendidikan dalam menghadapi suatu proses supervisi (Supardi, 2013: 93). Dalam model ini supervisor dapat menggunakan jendela nomor tiga dari empat jendela model jendela johari untuk meningkatkan prestasinya, yaitu: a) Dasar pegangan pengetahuan pendidikan guru dalam aspek tingkah laku pembelajaran adalah sama dengan pengetahuan supervisi klinik; b) Guru mempunyai dasar pegangan pengetahuan pendidikan dan tingkah laku pembelajaran, tetapi supervisor tidak mengetahuinya. Oleh karena itu, guru merasa bimbang jika supervisor mengekploitasikan dirinya dan ruang ini sepatutnya diperkecil; c) supervisor mempunyai dasar pengetahuan pendidikan dan praktik-praktik profesionalisme, tetapi guru tidak mempunyai dasar pegangan pengetahuan yang cukup; dan d) supervisor dan guru tidak mempunyai dasar pegangan pengetahuan pendidikan dan praktik-praktik profesional. Dan pada jendela ini perlu diperkecil melalui supervisi klinik dan kesepahaman akan dapat diwujudkan antara kedua belah pihak (supardi, 2013: 94-95).

Ketiga, model supervisi berbeda yaitu dengan menerapkan konsep bahwa setiap guru memiliki masing-masing perbedaan, sehingga proses supervisi yang dilakukan tidak dapat disama ratakan. Supervisi berbeda diperkenalkan oleh Glatthorn, yang dnilai lebih humanis dan memberikan ruang yang luas kepada guru untuk memilih bentuk supervisi yang diinginkan berdas kepada kesesuaian kesuburan kognitif mereka. Dengan kata lain, guru yang berbeda memerlukan supervisi yang berbeda bergantung kepada tahap kecakapan dan kemampuan pembelajaran masing-masing (supardi, 2013: 95). Bahkan, Aedi (2014: 6I) menganggap bawa model supervisi ini selaras dengan anggapan bahwa pendidikan merupakan suatu seni (artistik).

Keempat, model supervisi bersama yaitu sebuah model supervisi yang diperkenalkan oleh Lovels dan Wiles, dengan menekankan kolaboratif (saling membantu) dengan menggunakan segala sumber dan kepakaran yang ada pada pihak supervisior dan guru yang disupervisi atau guru yang disupervisi dengan guru lainnya untuk menghasilkan keberhasilan observasi di kelas.

Jurnal Manajemen Pendidikan, Vol 12, No 2., 
Supervisor dan guru bertukar pendapat, pandangan, ide, saran dan bersama-sama mencapai persetujuan (atau kata sepakat) dalam proses supervisi dengan mengabaikan faktor kekuasaan, yaitu siapa yang paling berkuasa untuk membuat keputusan. (Supardi, 2013: 95). Aedi (2014: 66) juga menegaskan bahwa supervisi kolaboratif merupakan proses yang melibatkan orang dengan keahlian yang beragam bekerja sama dalam status yang sama dan dengan komitmen yang sama untuk mencapai tujuan bersama pula, dengan tujuan akhir dapat saling mendorong para guru untuk membantu dan mendukung guru yang lain daam memperbaiki praktik pembelajaran di kelas.

Kelima, model supervisi inkuiri diterapkan dengan tuntutan bagi guru untuk melaksanakan penelitian tindakan kelas. Sebagaimana dikemukakan oleh Supardi (2013: 96) bahwa supervisi inkuiri merupakan suatu pendekatan yang merujuk kepada kajian yang dilakukan sendiri oleh guru melalui refleksi terhadap pembelajarannya, dengan tujuan untuk memperbaiki mutu pembelajarannya. Penelitian ini snagat bagus dilakukan oleh guru, sebagiamana dikemukakan oleh Pidarta (1992: 290) bahwa penelitian memiliki tujuan untuk mencari kebenaran-kebenaran secara ilmiah, kemudian memanfaatkannya dalam kehidupan sambil mengontrol secara kontinu. Sementara itu, Lucio juga memberikan pendapat tentang misi atau tujuan penelitian pendidikan, yaitu "the mission of educational research may be stated thus: (I) to provide objective evidence to improve school learning, (2) to help place the work of the school on firmer ground with the consumers of education, (3) to controvert myths, and (4) to change beliefs and attitudes". Penelitian Tindakan Kelas (PTK) yang diterapkan oleh guru sebagia wujud supervisi inkuiri tersebut merupakan salah satu upaya yang dapat dilakukan guru untuk meningkatkan kualitas tupoksi guru khususnya dalam pengelolaan pembelajaran. Melalui PTK, guru dapat meningkatkan kinerjanya secara terus menerus, dengan cara melakukan refleksi diri (self reflection), yakni upaya menganalisis untuk menemukan kelemahan-kelemahan dalam proses pembelajaran yang dilakukannya Bahkan bermanfaat bagi guru itu sendiri juga bagi pemangku kepentingan dalam merumuska pendidikan secara lebih berkualitas lagi (Sanjaya, 2009: 13; Arifin, 20I I: 8). Praktisnya, supervisi ini dilaksanakan dengan ciri yaitu: I) Dilaksanakan secara terencana dan kontinu, 2) Sistematis dan menggunakan prosedur serta teknik tertentu, 3) Menggunakan instrumen pengumpulan data, dan 4) Ada data yang objektif yang diperoleh dari keadaan riil (Sahertian, 2000: 26).

Keenam, model supervisi klinik dilaksanakan dengan pelaksanaan observasi oleh supervisor di dalam kelas saat guru melangsungkan pembelajaran. Model yang diperkenalkan oleh Cogan dan dikembangkan oleh Goldhammer dan rekan-rekannya, difokuskan pada perbaikan pengajaran dengan melalui sikus yang sistematis dari tahap perencanaan, pengamatan, dan analisis intelektual yang intensif terhadap penampilan mengajar sebenarnya dengan tujuan untuk mengadakan modifikasi yang rasional. Supervisi ini merupakan suatu proses pembimbingan dalam pendidikan bagi guru yang diobservasi (Supardi, 2013: 93; Purwanto, 2004: 88; Sahertian, 2000: 37). Mulyasa (2013a: 256-257) juga memberikan beberapa tips dan trik dalamp penerapan model supervisi klinik yaitu: I) membangun kesadaran, 2) meningkatkan pemahaman, 3) kepedulian, dan 4) komitmen.

Ketujuh, model supervisi gabungan yakni pelaksanannya menggabungkan antara konsep supervisi saintifik/ inkuiri, klinis dan artistik/ supervisi berbeda, yang disasarkan pada teori dan praktik supervisi serta evaluasi pembelajaran. Supervisor dapat menggunakan model saintifik untuk mengidentifikasi hal-hal yang seharusnya terjadi berdasarkan temuan empiris, kemudian model artistik dalam model gabunan ini digunakan untuk seni menafsirkan dan interpretasi atas apa yang terjadi di dalam kelas. Selanjutnya model supervisi klinis digunakan untuk memperbaiki atau menyelesaikan permasalahan pembelajaran (Aedi, 2014: 62-63). Dengan demikian, dapat dipahami bahwa model supervisi gabungan ini tampaknya memberikan ruang lebih fleksibel dan komprehensif terhadap penilaian yang dilakukan supervisor dalam rangka 
pelaksanaan supervisi. Dengan adanya gabungan tersebut, supervisor dapat melakukan pengamatan sesuai teori, praktik serta evaluasinya.

Dalam penerapan tujuh variasi model supervisi tersebut dilaksanakan untuk menghasilkan perbaikan sistem pembelajaran dan manajemen sekolah agar lebih berkualitas. Meskipun demikian, pelaksanaan variasi model supervisi tersebut tidak dilaksanakan secara utuh dan terstruktur dalam suatu periode tertentu. Variasi tersebut snagat berkaitan erat dengan situasi, kondisi, dan analisa kebutuhan sekolah.

\section{6) Strategi Supervisi Pembelajaran pada Kurikulum Khusus}

Pelaksanaan supervisi pembelajaran terkait kurikulum yang diterapkan di Madina Islamic School, mempunyai cara khusus. Hal tersebut dikarenakan di Madina Islamic School menerapkan tiga kurikulum yakni DIKNAS, al-Azhar Cairo, dan CAMBRIDGE.

Pada kurikulum berbasis al-Azhar Cairo pelaksanaan supervisi terhadap hasil belajar siswa yaitu melalui hafalan/tahfidz peserta didik. Sedangkan pada kurikulum Cambridge dilihat dari progression test peserta didik. Report perkembangan siswa wajib dilaporkan setiap 3 bulan sekali dan kemudian dilakukan analisis bersama-sama.

Sekolah yang menerapkan beberapa kurikulum mayoritas memiliki kebijakan tersendiri baik dalam perancangan, pelaksanaan, hingga evaluasi. Termasuk juga di dalamnya dalam rangka supervisi pembelajarannya. Supardi (2013: 91) menegaskan bahwa supervisor dapat menyumbangkan perubahan dalam kandungan pembelajaran dan bahan pembelajaran untuk keberhasilan pembelajaran. Supervisor dapat berperan mengendalikan, membantu, dan menilai pengembangan kurikulum di sekolah. Sehingga supervisor dan guru dapat bekerja sama dalam peningkatan pembelajaran bagi peserta didik.

\section{7) Report Supervisi Pembelajaran Memiliki Kriteria Khusus}

Penerapan penilaian hasil supervisi guru diserahkan oleh supervisor atau pihak manajemen sekolah kepada guru dalam bentuk report dengan kriteria penilaian yang ditentukan oleh sekolah. Dalam report tersebut terdapat kriteria aspek-aspek yang dinilai oleh supervisor berikut nilai angka, nilai huruf beserta catatan. Tolok ukur atau indikator keberhasilan guru dalam pembelajaran menggunakan persentase penilaian seperti nilai $A$ di atas $90 \%$, nilai B di atas $80 \%$ dan tidak lebih dari $90 \%$, dan seterusnya. Soekartawi (1995: 38) menegaskan bahwa kriteria penilaian sangat diperlukan guna menghidari kesalahan-pahaman antara pemimpin dan yang dipimpin dalam pelaksanaan suatu kegiatan monitoring dan evaluasi. Dengan demikian, dalam pelaksanaan sebuah monitoring dan evaluasi sangat diperlukan penentuan kriteria penilaian, sehingga hasil yang didapatkan dapat secara otentik dan optimal.

Prosentase atau kriteria penilaian tersebut sangat berpengaruh terhadap perlakuan yang didapat guru untuk program pengajaran pada tahun ajaran baru berikutnya di SD Madina Islamic School. Bagi guru yang memiliki kekurangan (mendapat nilai $\mathrm{C}$ ke bawah) dalam cara mengajarnya makan akan mendapat panggilan dan bimbingan khusus. Pidarta (2004: 135), mengemukakan bahwa penilaian yang sistematis dilakukan dalam aspek performan dan potensi. Penilaian performan mencakup prestasi kerja, cara bekerja, dan kepribadian. Sedangkan penilaian potensi mencakup pengembangan profesi berupa kreativitas dan hasil belajar. Oleh karena itu, pengaruh penilaian yang didapatkan guru setelah supervisi tersebut erat kaitannya dalam rangka peningkatan mutu kinerja melalui aspek performan dan potensinya.

Pola pelaksanaan report dalam supervisi pembelajaran tersebut pada umumnya menggunakan panduan kegitaan monitoring dan evaluasi (MONEV). Muhaimin, dkk (20 I0: 373374) menegaskan bahwa kegiatan monitoring dan evaluasi dilakukan dengan tujuan supervisi, dalam rangka mengetahui proses berjalannya pembelajaran, menemukan hambatan, dan mengambil keputusan atas pemecahan masalahnya. Secara umum, kegiatan MONEV di sekolah/ Madrasah mencakup lima komponen yakni konteks, input, proses, output, dan outcome. 


\section{KESIMPULAN}

Supervisi pembelajaran dapat divariasikan antar model. Setiap modelnya digunakan sesuai dengan kebutuhan. Tujuan utamanya adalah peningkatan mutu pembelajaran, baik dari aspek personal, material, maupun operasional. Sekolah Madina Islamic School mengaplikasikan variasi model supervisi pembelajaran pada keterpaduan kurikulumnya. Melalui prinsip spontanitas, supervisi pembelajaran yang terlaksana bermanfaat pada habitualiasasi guru dalam pembelajaran. Kriteria penilaian menjadi aspek penting lainnya yang ditetapkan sekolah dalam pelaksanaan supervisi pembelajaran, guna menghasilkan penilaian dan bimbingan yang optimal, terarah, dan otentik.

\section{REFERENSI}

Aedi, Nur. (20l4). Pengawasan Pendidikan; Tinjauan Teroi dan Praktik. Jakarta. Rajawali Pers.

Arifin, Zainal. (20II). Penelitian Pendidikan. Bandung. PT Remaja Rosdakarya. Cet. I.

Depag RI, Dirjen Pembinaan Kelembagaan Agama Islam. (2000). Pedoman Pengembangan Administrasi dan Supervisi Pendidikan. Jakarta. Departemen Agama RI.

Lucio, William H. (1979). Supervision in Thought and Action; Third Edition. New York: Mc Graw Hill Book Company.

Muhaimin, dkk. (20l0). Manajemen Pendidikan; Aplikasinya dalam Penyusunan Rencana Pengembangan Sekolah/ Madrasah. Jakarta. Kencana. Cet. 2.

Mulyasa, E. (20I3a). Manajemen dan Kepemimpinan Kepala Sekolah. Kakarta. Bumi Aksara. 12

Pidarta, Made. (2004). Manajemen Pendidikan Indonesia; Edisi Revisi. Jakarta. PT. Rineka Cipta. Cet. 2.

(1992). Pemikiran tentang Supervisi Pendidikan. Jakarta. Bumi Aksara. Cet. I.

Purwanto, Ngalim. (2004). Administrasi dan Supervisi Pendidikan. Bandung. Remaja Rosdakarya.

Rahayu, Cici Marlina. JPPI: Indeks Pendidikan Indonesia di Bawah Ethiopia dan Filipina. Detik

News Online. Diposting pada 23 Maret 2017. (https://news.detik.com/berita/d34547/2/jppi-indeks-pendidikan-indonesia-di-bawah-ethiopia-dan-filipina)

Sagala, Syaiful. (20I3). Administrasi Pendidikan Kontemporer. Bandung. Alfabeta. Cet. 7.

Sahertian, Piet A, dan Ida Aleida Sahertian. (1990). Supervisi Pendidikan. Jakarta. Rineka Cipta.

(2000). Konsep Dasar dan Teknik Supervisi Pendidikan dalma Rangka Pengembangan Sumber Daya Manusia. Jakarta. PT Rineka Cipta.

Sanjaya, Wina. (2009). Penelitian Tindakan Kelas. Jakarta. Kencana. Cet. I.

Soekartawi. (1995). Monitoring dan Evaluasi Proyek Pendidikan. Jakarta. PT. Dunia Pustaka Jaya. Supardi. (20I3). Kinerja Guru. Jakarta. PT. RajaGrafindo Persada. Cet. I.

Wawancara dengan Kepala Sekolah SD Madina Islamic School pada 29 November 2016. 